\title{
Therapeutic Effect of Nigella sativa Oil in Hepatotoxicity Induced by Isoniazid in Rats
}

\author{
Joydeep Paul', Mohammad Nasiruddin ${ }^{1, *}$, Irfan Ahmad Khan', Rahat Ali Khan', Sayeedul Hasan Arif ${ }^{2}$ \\ ${ }^{1}$ Department of Pharmacology, J.N.M.C.H., A.M.U, Aligarh- 202002,Uttar Pradesh, INDIA. \\ ${ }^{2}$ Department of Pathology, J.N.M.C.H., A.M.U, Aligarh- 202002, Uttar Pradesh, INDIA.
}

\begin{abstract}
Objectives: Tuberculosis is one the most prevalent microbial diseases worldwide and hepatotoxicity is one of the major side effects of first line anti-tubercular drug, Isoniazid. The reported pharmacological activities of Nigella sativa oil include protection from liver damage caused by diseases, chemicals and chemotherapeutic agents. The aim of the present study was to evaluate therapeutic potential of Nigella sativa oil in hepatotoxicity induced by using Isoniazid. Methods: Isoniazid $(50 \mathrm{mg} / \mathrm{kg}$ ) was administered to all the animals for 28 days orally. Silymarin $(50 \mathrm{mg} / \mathrm{kg})$ was used as standard drug for this study. From $29^{\text {th }}$ day onwards isoniazid was stopped and therapeutic agents - normal saline, silymarin, Nigella sativa oil $0.5 \mathrm{ml} / \mathrm{kg}$ and $1 \mathrm{ml} / \mathrm{kg}$ were given orally for the next 15 days in different animal groups respectively. On $44^{\text {th }}$ day rats were sacrificed, blood samples were collected for biochemical analysis and liver tissue was subjected to histopathological examination. Results: The rats treated with $N$. sativa oil showed significant reduction in the liver enzymes and total bilirubin levels when compared to negative control group. There was also significant improvement in the histopathological scores in $N$. sativa oil treated group when compared to the negative control group. Conclusion: This study demonstrates the effectiveness of Nigella sativa oil as a therapeutic agent in hepatotoxicity induced by isoniazid in a dose dependant manner.
\end{abstract}

Key words: Nigella sativa, Hepatoprotective, Isoniazid, Silymarin, Tuberculosis, Hepatotoxicity.

\section{INTRODUCTION}

Tuberculosis is one the most prevalent microbial diseases worldwide. According to the WHO, India had the highest TB burden worldwide for the year 2014, with approximate $23 \%$ out of the global estimate of new incidences. ${ }^{1}$ Hepatotoxicity is a well reported and documented adverse effect of the $1^{\text {st }}$ line antitubercular drugs, which often leads to discontinuation of the drugs and relapse or failure of the therapy. The first line antitubercular drugs, which have the highest reported hepatoxicity, are isoniazid and pyrazinamide and concomitant use of these drugs might lead to fulminant hepatitis with lethal consequences. ${ }^{2}$ The drug isoniazid continues to be a leading cause of drug induced hepatic injury in the United States and its hepatotoxicity has often been significantly under-reported. ${ }^{3}$ Elevations in the levels of hepatic transaminases are often encountered with the use of the drug Isoniazid. Severe hepatic injury is seen in approximately $1 \%$ of the people taking isoniazid. Liver damage in isoniazid therapy is found out to be age dependent, as it rarely in individuals taking this drug below the age of 20 , but the incidence of liver damage increases to $1.2 \%$ between the ages of 35 to 49 years and approximately $2.3 \%$ in the 50 and above age group. ${ }^{4}$ The hepatotoxicity of isoniazid in most cases is dose related, however some instances can be ascribed to drug hypersensitivity. The hepatic damage caused by the drug isoniazid can be related to genetic polymorphism in acetylation of this drug whereas other risk factors include
Submission Date: 12-06-2018; Revision Date: 24-10-2018; Accepted Date: 14-11-2018

DOI: 10.5530/ijper.53.2.32 Correspondence: Prof. Mohammad Nasiruddin, Professor and Chairman, Departmentof Pharmacology, J.N.M.C.H., A.M.U, ALIGARH- 202002, Uttar Pradesh, INDIA. Phone: +919421586898 E-mail: naseer_bettiah@ yahoo.co.in

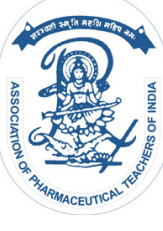

www.ijper.org 
old age, malnutrition, alcoholism, HIV infection and Hepatitis B or C infection. ${ }^{5}$

Plant derivatives with purported hepatoprotective activity have been used in folk medicine and traditional systems of medicine around the world for centuries. Nigella sativa $\mathrm{L}$. (Black cumin) is an herbaceous plant, which has used since time immemorial for treatment of various ailments in different systems of traditional medicine. ${ }^{6}$ Nigella sativa seed possess various reported pharmacological properties like analgesic, anti-inflammatory, antipyretic, antineoplastic, antioxidant and others. ${ }^{7-9}$ The hepatoprotective activity of Nigella sativa has also been explored. ${ }^{10,11}$ But there are only few reports regarding the protective activity of Nigella sativa seeds against antitubercular drug induced hepatotoxicity. In view of the above, this study was planned to evaluate the therapeutic aspect of Nigella sativa oil in isoniazid induced hepatotoxicity in rats.

\section{MATERIALS AND METHODS}

\section{Experimental Animals}

Adult wistar albino rats of either sex (150-200g) were obtained from Central Animal House, Jawaharlal Nehru Medical College; Aligarh Muslim University, Aligarh, U.P. They were housed under standard conditions (temperature $27 \pm 2{ }^{\circ} \mathrm{C}$, Humidity $30-70 \%$ and $12 \mathrm{~h}$ light/dark cycles). They were fed with standard pellet diet and water ad libitum. The rats were acclimatized to the laboratory condition for 1 week prior to the experiments. The study protocol was approved by the Institutional Animal Ethics Committee (IAEC) on 20.12.2014. All the animal experiments were carried out as per the rules and regulations of IAEC and CPCSEA.

\section{Drugs and chemicals}

- Nigella sativa oil (Kalonji oil) was obtained from (Mohammedia products, Aamirnagar, Shah Sahab Mohalla, Karimnagar - 505001, Telengana State., India).

- Isoniazid Dispersible Tablets (Macleod's Pharmaceuticals Ltd. Mumbai, Maharashtra India).

- Normal Saline (Swaroop Pharmaceuticals Pvt. Ltd. Aligarh).

- Silymarin suspension (Micro Labs Ltd. Bengaluru, Karnataka, India) was used as the standard drug for the purpose of this study.

Diagnostic kits used for the purpose of this study were Bilirubin kit (Accurex Biomedicals pvt. Ltd., Mumbai, India), Aspartate transaminase (AST), Alanine transaminase (ALT) kits - Span Diagnostics Ltd. (Surat, India.) and
Alkaline Phosphatase (ALP) kit - Beacon Diagnostics, Gujrat India.

\section{Induction of hepatotoxicity}

Hepatotoxicity was induced in the animals by using isoniazid $50 \mathrm{mg} / \mathrm{kg}$ orally for 28 days. ${ }^{12}$

\section{Experimental design}

Thirty albino rats of either sex, weighing 100-200 g were divided into five groups of 6 animals each. All the drugs were administered orally.

Isoniazid dispersible tablets were dissolved in distilled water and administered to all the animals for 28 days orally. From $29^{\text {th }}$ day onwards isoniazid was stopped and the therapeutic agent's normal saline, silymarin $50 \mathrm{mg} / \mathrm{kg}^{13}$ or Nigella sativa oil $0.5 \mathrm{ml} / \mathrm{kg}$ and $1 \mathrm{ml} / \mathrm{kg}$ were given orally for the next 15 days (Table 1).

The animals were sacrificed, blood samples were collected from the heart of animals using open approach on $44^{\text {th }}$ day and were subjected to biochemical analysis (Serum Billirubin, AST, ALT and ALP), liver removed and physical parameters (weight of the liver per 100 gram of rat's weight and volume of the liver in $\mathrm{ml}$ per 100 gram of the rat's weight) were recorded. The liver tissues were then subjected to histo-pathogical analysis.

\section{Biochemical analysis}

The blood samples were collected by cardiac puncture (open approach) and centrifuged at $5000 \mathrm{rpm}$ for $10 \mathrm{~min}$, plasma was separated and subjected to biochemical analysis. Total bilirubin was estimated using the method described by Jendrassik L. et al. $1938^{14}$ using reagent supplied by Accurex Biomedicals Pvt Ltd. India. AST and ALT levels were determined by the Reitman and Frankel $^{15}$ method using kits acquired from Span Diagnostics Ltd. (Surat, India). Serum ALP levels were estimated by King's method ${ }^{16}$ using the ALP determination kit procured from Beacon Diagnostics, Gujrat India.

\section{Histological Examination}

The liver samples were preserved in 10\% formalin for $48 \mathrm{~h}$, fixed in paraffin. The tissue samples were processed according to standard histological techniques

\begin{tabular}{|c|c|c|}
\hline \multicolumn{3}{|c|}{ Table1: Grouping of Animals. } \\
\hline Groups & Day1-28 & Day $29-43$ \\
\hline Group I & Normal saline $1 \mathrm{ml} / \mathrm{kg}$. & Normal saline $1 \mathrm{ml} / \mathrm{kg}$. \\
\hline Group II & Isoniazid $50 \mathrm{mg} / \mathrm{kg}$. & Normal saline $1 \mathrm{ml} / \mathrm{kg}$. \\
\hline Group III & Isoniazid $50 \mathrm{mg} / \mathrm{kg}$. & Silymarin $50 \mathrm{mg} / \mathrm{kg}$. \\
\hline Group IV & Isoniazid $50 \mathrm{mg} / \mathrm{kg}$. & Nigella sativa oil $0.5 \mathrm{ml} / \mathrm{kg}$. \\
\hline Group V & Isoniazid $50 \mathrm{mg} / \mathrm{kg}$. & Nigella sativa oil $1 \mathrm{ml} / \mathrm{kg}$. \\
\hline
\end{tabular}


and stained with hematoxylin and eosin. ${ }^{17}$ The assessment of damage of liver tissue was done by method described by described by Davidson C.S. $1979 .{ }^{18}$ The various parameters used were degeneration, necrosis, fibrosis and regeneration.

The percent of hepatoprotection offered by the standard and test drug was calculated using the formula:

$$
\mathrm{H}=\left[1-\left(\frac{\mathrm{T}-\mathrm{V}}{\mathrm{C}-\mathrm{V}}\right)\right] \times 100
$$

Where $\mathrm{H}=$ Percentage of hepatoprotection, $\mathrm{T}=$ Mean value of group treated with test drugs, $\mathrm{C}=$ Mean value of group treated with Isoniazid, $\mathrm{V}=$ Mean value for normal control group animals.

\section{Statistical analysis}

The data of study are expressed as Mean \pm Standard Error of Mean (SEM). The groups were compared by one way analysis of variance (ANOVA) followed by post hoc Tukey's test to analyze the statistical significance. $P$ value of less than 0.05 was considered significant for this study.

\section{RESULTS}

\section{Effects of $N$. sativa oil on the liver function parameters in isoniazid treated rats}

The biochemical parameters studied were total bilirubin, AST (aspartate aminotransferase), ALT (alanine aminotransferase) and ALP (alkaline phosphatase). In the negative control (Group II) group the liver function parameters total bilirubin $(p<0.001)$, AST $(p<0.001)$ and ALT $(p<0.001)$ showed significant rise and ALP level was also raised significantly $(P<0.01)$ in comparison to the normal control group (Group I). All the liver function parameters except ALP in the animals of the positive control group (III) showed significant reduction, total bilirubin $(p<0.001)$, AST $(p<0.001)$ and ALT $(p<0.001)$ in comparison to the negative control group (Group II). ALP values in the positive control group (Group III) also showed reduction but were not statistically significant when compared to the negative control group (Group II). In the rats of the N. sativa oil low dose group (Group IV) bilirubin levels showed significant $(p<0.001)$ reduction in comparison to the negative control group (Group II). Serum ALT levels also exhibited significant $(p<0.01)$ reduction, serum AST and ALP levels were reduced but were not statistically significant in comparison to the negative control group (Group II). The animals treated with N. sativa oil high dose (Group V) exhibited significant reduction in the levels of total billirubin $(p<0.001)$, AST $(p<0.01)$ and ALT $(p<0.001)$ when compared to the negative control group (Group II), the ALP levels also showed reduction in comparison to the negative control group (Group II) but it was not statistically significant (Table 2).

All data are expressed as Mean \pm SE. Negative control (Group II) group was compared with Normal control group (Group I) and all other groups (Group III, IV and V) were compared with Negative control group (Group II), $* p<0.05, * * p<0.01$ and ${ }^{* * *} p<0.001$ were considered significant.

\section{Percentage of Hepatoprotection offered by N. sativa oil low and high dose in isoniazid induced hepatotoxicity}

The hepatoprotection offered by the test drugs was estimated by formula described in the section of material and methods. The percentage of hepatoprotection was determined as a function of AST, ALT, ALP and Total bilirubin in all test groups as shown in Table 3. Percentage of hepatoprotection was highest for the positive control group (Group III) i.e. 81\%, 88\%, 83\% and 54 $\%$ for bilirubin AST, ALT and ALP respectively. Among the N. sativa oil test groups hepatoprotection for the low dose group (Group IV) was 65\%, 29\%, 58\% and $29 \%$

Table 3: Percentage of Hepatoprotection offered by
N. sativa in INH treated rats.
\begin{tabular}{|c|c|c|c|c|c|} 
S.N. & $\begin{array}{c}\text { Groups } \\
\text { n=6 }\end{array}$ & \multicolumn{4}{|c|}{ Hepatoprotection (\%) } \\
\cline { 2 - 6 } & T. Bilirubin & AST & ALT & ALP \\
\hline 1 & Silymarin & 81 & 88 & 83 & 54 \\
\hline 2 & N. sativa oil $0.5 \mathrm{ml} / \mathrm{kg}$ & 65 & 29 & 58 & 29 \\
\hline 3 & N. sativa oil $1 \mathrm{ml} / \mathrm{kg}$ & 72 & 66 & 72 & 36 \\
\hline
\end{tabular}

\begin{tabular}{|c|c|c|c|c|}
\hline \multicolumn{2}{|c|}{ Table 2: Therapeutic effect of $\mathbf{N}$. sativa oil on biochemical parameters in INH treated rats. } \\
\hline Groups(n= 6) & $\begin{array}{c}\text { T. Bilirubin } \\
\text { (mg/dl) }\end{array}$ & $\begin{array}{c}\text { S. AST } \\
\text { (units/l) }\end{array}$ & $\begin{array}{c}\text { S. ALT } \\
\text { (units/l) }\end{array}$ & $\begin{array}{c}\text { S.ALP } \\
\text { (units/l) }\end{array}$ \\
\hline Group I (N. saline 43 days) & $0.29 \pm 0.42$ & $44.40 \pm 5.01$ & $20.64 \pm 5.75$ & $56.40 \pm 4.82$ \\
\hline Group II (INH for 28days + N. saline for 15 days) & $1.86 \pm 0.19^{* * *}$ & $115.40 \pm 6.35^{* * *}$ & $116.76 \pm 12.13^{* * *}$ & $118.36 \pm 7.40^{* *}$ \\
\hline Group III (INH for 28 days + Silymarin for 15 day) & $0.59 \pm 0.13^{* * *}$ & $52.64 \pm 10.68^{* * *}$ & $36.60 \pm 10.14^{* * *}$ & $85.18 \pm 12.96$ \\
\hline Group IV(INHfor28 days + N. sativa 0.5ml/kg for 15 days) & $0.84 \pm 0.05^{* * *}$ & $94.62 \pm 4.26$ & $61.30 \pm 5.96^{* *}$ & $100.88 \pm 5.52$ \\
\hline Group V (INH for 28days+ N. sativa 1ml/kg for 15 days) & $0.73 \pm 0.03^{* * *}$ & $68.38 \pm 12.78^{* *}$ & $47.11 \pm 10.15^{* * *}$ & $94.20 \pm 13.35$ \\
\hline
\end{tabular}




\begin{tabular}{|c|c|c|c|c|}
\hline $\begin{array}{l}\text { Groups } \\
n=6\end{array}$ & Degeneration & Necrosis & Fibrosis & Regeneration \\
\hline $\begin{array}{l}\text { Group I } \\
\text { N. saline for } 43 \text { days }\end{array}$ & 0 & 0 & 0 & 0 \\
\hline $\begin{array}{l}\text { Group II } \\
\text { (INH for 28days+N. saline for } 15 \text { days) }\end{array}$ & $2.75 \pm 0.25^{* * *}$ & $2.25 \pm 0.25$ & $3.00 \pm 0.40^{* * *}$ & 0 \\
\hline $\begin{array}{c}\text { Group III } \\
\text { (INHfor28 days+ Silymarin for } 15 \text { day) }\end{array}$ & $0.50 \pm 0.29^{* * * *}$ & $0.75 \pm 0.48^{*}$ & $1.25 \pm 0.47^{*}$ & $2.75 \pm 0.25^{* * *}$ \\
\hline $\begin{array}{c}\text { Group IV } \\
\text { (INHfor28 days+ N. sativa low dose for } 15 \text { days) }\end{array}$ & $1.75 \pm 0.25$ & $1.25 \pm 0.25$ & $2.25 \pm 0.25$ & $1.75 \pm 0.25^{*}$ \\
\hline $\begin{array}{c}\text { Group V } \\
\text { (INH for 28days }+N \text {. sativa high dose for } 15 \text { days) }\end{array}$ & $0.75 \pm 0.25^{* *}$ & $1.00 \pm 0.40^{*}$ & $1.5 \pm 2.89^{*}$ & $2.50 \pm 0.28^{* * * *}$ \\
\hline
\end{tabular}

for bilirubin AST, ALT and ALP respectively and $72 \%$, $66 \%, 72 \%$ and $36 \%$ for the high dose group (Group V).

\section{Effects of $N$. sativa oil on the histopathological examination in isoniazid treated rats}

The histopathological parameters studied were degeneration, necrosis, fibrosis and regeneration. The microscopic architecture of the liver appeared to be normal in the normal control group (Group I) with no degeneration, necrosis and fibrosis. In the negative control group (Group II) the liver histopathological score was grossly deranged with significant degeneration $(p<0.001)$, necrosis $(p<0.001)$ and fibrosis $(p<0.001)$ with no regeneration in comparison to normal control group (Group I).In the positive control group (Group III) the liver histopathological scores showed improvement. The degeneration $(p<0.001)$, necrosis $(p<0.05)$ and fibrosis $(p<0.05)$ scores exhibited significant reduction and also there was significant increase in regeneration $(p<0.001)$ in comparison to the negative control group (Group II). In N. sativa oil low dose group (Group IV), there was a decrease in the degeneration, necrosis and fibrosis scores but were not statistically significant and also there was significant regeneration $(p<0.01)$ in comparison to the negative control group (Group II). In N. sativa oil high dose group (Group V) the degeneration $(p<0.01)$, necrosis scores $(p<0.05)$ and fibrosis scores $(p<0.05)$ exhibited significant reduction and also there was significant regeneration $(p<0.001)$ in comparison to the negative control group (Group II) (Table 4).

All data are expressed as Mean \pm SE. Negative control (Group II) group was compared with Normal control group (Group I) and all other groups (Group III, IV and V) were compared with Negative control group (Group II), ${ }^{*} p<0.05,{ }^{* *} p<0.01$ and ${ }^{* * *} p<0.001$ were considered significant.

\section{DISCUSSION}

In day to day life, human body comes in contact with various toxins related to environment, indirectly. Ailments of liver are on the rise in the $21^{\text {st }}$ century. The spectrum of liver disorders is vast and it ranges from hepatitis to cirrhosis of diverse etiologic origins such as viral diseases, autoimmune disorders; drug induced liver injury and different types of carcinomas. Despite advances in modern medicine there is no definitive cure for liver disorders. So, there is an emergent need to develop potent agents, which not only prevent hepatic damage but also be curative.

The drug isoniazid (INH) is one of the $1^{\text {st }}$ line drugs used for prophylaxis as well as treatment of tuberculosis. INH is associated with significant hepatotoxicity. Hepatotoxicity in patients on INH treatment is encountered in approximately $2 \%$ cases, which if not recognized timely can have fatal outcome. ${ }^{19} \mathrm{INH}$ was found out to be the leading cause of drug induced liver injury in the United States and hepatotoxicity resulting from the use of INH treatment is significantly underreported. ${ }^{20}$ The presumed mechanism of INH hepatotoxicity is that INH gets converted to acetylisoniazid by the enzyme NAT2 which then gets eliminated by the kidney; acetylisoniazid further gets transformed into acetylhydrazine and then to potential hepatotoxic metabolite acetyl diazine by the CYP enzymes which is toxic by itself as it gets converted to reactive acetyl onium ion, acetyl radical and ketene, which binds covalently to hepatic macromolecules causing irreversible damage to the hepatocytes. ${ }^{21}$ In the present study INH was given to rats orally in a dose of $50 \mathrm{~m} / \mathrm{kg}$ for 28 days to induce hepatotoxicity.

In India herbal therapy for liver ailments based on the traditional systems of medicine has been used for a long time. Despite the commercial popularity of several 
herbal remedies for liver diseases in particular, they still remain unacceptable treatment modalities. In order to develop effective drugs for liver disease based on the knowledge of the traditional systems proper therapeutic evaluation of herbal products in animal models are imperative. It is of utmost importance to carefully combine the knowledge of the traditional systems of medicine with that of the modern concept of evidencebased medicinal evaluation, standardization and randomized placebo controlled clinical trials to support clinical efficacy of the new drug. ${ }^{22}$ The seeds of Nigella sativa plant have a long history of being a diversely beneficial for numerous ailments. For thousands of years people all over the world have used the Black Seed to cure diseases and sustain health in general. Many studies have been conducted to demonstrate the hepatoprotective activity of N. sativa plant. ${ }^{23,24}$ Also Trivedi et.al in 2013 demonstrated the hepatoprotective activity of thymoquinone, which is the active principle of Nigella sativa seed oil against the antitubercular drug induced hepatotoxicity in rats has been reported. ${ }^{25}$

In the present study we explored the hepatoprotective potential of the N. sativa oil in isoniazid (INH) induced hepatic damage in rats. The results of the biochemical parameters depicts that after 15 days of treatment with $N$. sativa oil $0.5 \mathrm{ml} / \mathrm{kg}$ and $1 \mathrm{ml} / \mathrm{kg}$ in $\mathrm{INH}$ induced hepatotoxicity there was reduction in the AST, ALT and billirubin levels significantly in comparison to the negative control group. All the liver function parameters except ALP in the animals of the positive control group showed significant reduction, T. bilirubin $(p<0.001)$, AST $(p<0.001)$ and ALT $(p<0.001)$ in comparison to the negative control group. ALP value in the positive control group also showed reduction but was not statistically significant when compared to the negative control group. In the rats of the $N$. sativa oil $0.5 \mathrm{ml} / \mathrm{kg}$ group bilirubin level showed significant $(p<0.001)$ reduction in comparison to the negative control group. Serum ALT level also exhibited significant $(p<0.01)$ reduction, serum AST and ALP levels were reduced but were not statistically significant in comparison to the negative control group. The animals treated with $N$. sativa oil $1 \mathrm{ml} / \mathrm{kg}$ exhibited significant reduction in the levels of total billirubin $(p<0.001)$, AST $(p<0.01)$ and ALT $(p<0.001)$ when compared to the negative control group, the ALP level also showed reduction in comparison to the negative control group but it was not statistically significant. The percentage of hepatoprotection offered by $\mathrm{N}$. sativa oil $0.5 \mathrm{ml} / \mathrm{kg}$ dose was $65 \%, 29 \%, 58 \%$ and $29 \%$ for bilirubin AST, ALT and ALP respectively. The percentage of hepatoprotection in the $1 \mathrm{ml} / \mathrm{kg}$ dose group was $72 \%, 66 \%, 72 \%$ and $36 \%$ for bilirubin AST, ALT and ALP respectively

The hepatoprotective activity of N. sativa oil shown in the biochemical parameters are supported by the findings of the histopathological examination in the therapeutic study. The histopathological parameters studied were degeneration, necrosis, fibrosis and regeneration. In N. sativa oil $0.5 \mathrm{ml} / \mathrm{kg}$ dose group, there was a decrease in the degeneration, necrosis and fibrosis scores but were not statistically significant and also, there was significant regeneration $(p<0.01)$ in comparison to the negative control group. In $N$. sativa oil $1 \mathrm{ml} / \mathrm{kg}$ group the degeneration $(p<0.01)$, necrosis scores $(p<0.05)$ and fibrosis scores $(p<0.05)$ exhibited significant reduction and also there was significant regeneration $(p<0.001)$ in comparison to the negative control group. Both the doses of $N$. sativa oil showed therapeutic efficacy against INH induced liver injury by decreasing the elevation of AST, ALT, ALP and Total bilirubin. But the effect was more pronounced with $N$. sativa $1 \mathrm{ml} / \mathrm{kg}$ dose. N. sativa oil $1 \mathrm{ml} / \mathrm{kg}$ provided greater hepatoprotective effect. Comparative histopathological study of the liver from different groups of rats corroborated the hepatoprotective activity of $N$. sativa oil). Liver sections of the animals treated with $N$. sativa oil $0.5 \mathrm{ml} / \mathrm{kg}$ and $1 \mathrm{ml} / \mathrm{kg}$ dose exhibited significant liver protection against INH in this study, which is evident by the presence of regenerating and lesser degenerating hepatocytes, fibrotic bridges and necrotic foci in the prophylactic study. The protection offered by N. sativa oil $1 \mathrm{ml} / \mathrm{kg}$ dose though somewhat lesser than the standard drug silymarin but was considerable when compared to the liver slices of the rats treated with isoniazid (INH) alone.

Oxidative stress has been postulated as one of the major mechanisms by which the antitubercular drugs, namely isoniazid (INH) and rifampicin cause damage to the hepatocytes. After combined treatment of INH and rifampicin the glutathione and related thiols, which serve the purpose of preventing tissue from oxidative damage, get reduced significantly in blood and liver tissue. The result of which is microvesicular deposition of fats in the hepatocytes and inflammation of the portal triad. Thus isoniazid's (INH) hepatotoxicity appears to be mediated by oxidative stress. ${ }^{26}$ The hepatoprotective activity of the $N$. sativa oil can be ascribed to its well documented pharmacological properties like anti-inflammatory property which might be capable of preventing inflammatory damage to the liver tissue. ${ }^{27}$ The probable mechanism by which $N$. sativa oil offers protection against antitubercular drug induced hepatotoxicity may be due to its immunomodulatory and antioxidant activity. ${ }^{28}$ 
Thymoquinone, active constituent of $N$. sativa oil has been reported to possess antioxidant and antiperoxidative effects. ${ }^{29}$ This active principle of $N$. sativa has been reported to effectively improve plasma and liver antioxidant activity. It also enhanced the liver antioxidant genes. ${ }^{30}$ The effectiveness of Thymoquinone, the active constituent of $N$. sativa in ameliorating the hepatotoxicity in rats induced by the antitubercular drugs used in combination has also been demonstrated. ${ }^{25}$

\section{CONCLUSION}

The findings of our study demonstrate that $N$. sativa oil administration significantly improved the liver biochemical and histological parameters in a dose dependent fashion. The hepatoprotective action of $N$. sativa oil might be ascribed to the presence of antioxidant phytochemicals which might have countered the free radical damage to the hepatocytes caused by isoniazid (INH). These were the results of a preliminary study and further detailed investigations are required to pinpoint the mechanism of hepatoprotection offered by $N$. sativa oil.

\section{ACKNOWLEDGEMENT}

We are thankful to J.N.M.C., A.M.U., Aligarh.

\section{CONFLICT OF INTEREST}

The authors declare no conflict of interest.

\section{ABBREVIATIONS}

ad libitum: At pleasure (as much as is wanted); ALP: Alkaline phosphatase; ALT: Alanine aminotransferase; AST: Aspartate aminotransferase; ${ }^{\circ} \mathbf{C}$ : Degree Centigrade; CYP: Cytochrome $\mathrm{P}_{450}$; dL: Deciliter; et al.: Et alia (and others); INH: Isoniazid (Iso-nicotinic Hydrazine); IU/L: International units per liter; mg: Milligram; min: Minute; ml.: Millilitre; mm: Millimeter; No.: Number; N. sativa: Nigella sativa; N.S.: Not significant; p.o.: Per oral; SE: Standard error; SEM: Standard error of mean; Sec: Second; s.c.: Subcutaneous; T. bill: Total billirubin; Via: By way of; viz.: Videlicet (namely); Vol.: Volume; v/v: Volume by volume; v/w: Volume by weight; wt.: Weight; \%: Percent; \&: And; $\alpha$ : Alpha; $\beta$ : Beta; $\gamma:$ Gamma; $\mu \mathrm{g}$ : Microgram; $\mu 1$ : Microliter; /: Oblique; $<$ : Less than; >: More than.

\section{REFERENCES}

1. Global tuberculosis report [Internet]. World Health Organization. 2016. [cited 3 January 2016]. Available from:http://www.who.int/tb/publications/global_ report/en.
2. Durand F, Bernuau J, Pessayre D, Samuel D, Belaiche J, Degott C, et al. Deleterious influence of pyrazinamide on the outcome of patients with fulminant or subfulminant liver failure during antituberculous treatment including isoniazid. Hepatology. 1995;21(4):929-32.

3. Hayashi PH, Fontana RJ, Chalasani NP, Stolz AA, et al. Under-reporting and Poor Adherence to Monitoring Guidelines for Severe Cases of Isoniazid Hepatotoxicity. Clinical Gastroenterology and Hepatology. 2015;13(9):1676-82.

4. Gumbo T. Chemotherapy of Tuberculosis, Mycobacterium Avium Complex Disease and Leprosy. In: Brunton LL, Chabner BA, Knollmann BC. (eds.) Goodman and Gilman's. The Pharmacological Basis of Therapeutics. $12^{\text {th }}$ ed. United States of America: The McGraw-Hill Companies Inc. 2011;1156-7.

5. Yew W, Leung C. Antituberculosis drugs and hepatotoxicity. Respirology. 2006;11(6):699-707.

6. Paarakh PM. Nigella sativa L. A comprehensive review. Indian Journal of Natural Products and Resources. 2010;1(4):409-29.

7. Rawoof KG, Suresh V, Dey T, Ata S, Singh JSD. Evaluation of antidiabetic, analgesic and antimicrobial activities of Nigella sativa. Contemporary Investigations and Observations in Pharmacy.2013;2(1):13-6.

8. Hasan MN, Khan RA, Nasiruddin M, Khan AA. Protective effect of Nigella sativa against aspirin induced gastric damage in rats. Int $\mathrm{J}$ Pharm Pharm Sci. 2014;6(5):275-8.

9. Hadjzadeh MAR, Keshavarzi Z, Yazdi SAT, Shirazi MG, Rajaei Z, Rad AK. Effect of alcoholic extract of Nigella sativa on Cisplatin-induced toxicity in rats. Iranian Journal of Kidney Diseases. 2012;6(2):99-104.

10. Al-Suhaimi EA. Hepatoprotective and immunological functions of Nigella sativa seed oil against hypervitaminosis $A$ in adult male rats. International Journal for Vitamin and Nutritional Research. 2012;82(4):288-97.

11. Hassan AS, Ahmed JH, Al-Haroon SS.A study of the effect of Nigella sativa (Black seeds) in isoniazid (INH)-induced hepatotoxicity in rabbits Indian Journal of Pharmacology. 2012;44(6):678-82.

12. Attri S, Rana SV, Vaiphei K, Sodhi CP, Katyal R, Goel RC, et al. Isoniazid- and rifampicin-induced oxidative hepatic injury — protection by $\mathrm{N}$-acetylcysteine. Human and Experimental Toxicology. 2000;19(9):517-22.

13. Singh G, Goyal R, Sharma P. Pharmacological potential of Silymarin in combination with Hepatoprotective plants against experimental Hepatotoxicity in rats. Asian Journal of Pharmaceutical and Clinical Research. 2012;5(s1):128-33.

14. Jendrassik L, Grof P. Method on photometric systems for in vitro determination of direct and total bilirubin. Bioche Zeitschrift. 1938;297:82-9.

15. Reitman S, Frankel S. A colorimetric method for the determination of serum glutamic oxalacetic and glutamic pyruvic transaminases. American Journal of Clinical Pathology. 1957;28(1):56-63.

16. King EJ, Kind PRM. In-vitro determination of serum alkaline phosphatase. Journal of Clinical Pathology.1972;7:321-2.

17. Culling CFA, Alliston RT, Barr WT. Cellular Pathology Technique [Internet]. $4^{\text {th }}$ ed. London: Butterworth and Co Ltd. 1985. [cited 29 May 2016]. Availablefrom: http://samples.sainsburysebooks.co.uk/9781483192192_sample_813090.pdf.

18. Davidson CS. Guidelines for detection of hepatotoxicty due to drugs and chemical. USA. USA: NIH publication, U.S. Department of Health and Education and Welfare NIH. 1979.

19. Sarich T, Zhou T, Adams SP, Bain Al, Wall RA, Wright JM. A model of isoniazid-induced hepatotoxicity in rabbits. Journal of Pharmacological and Toxicological Methods. 1995;34(2):109-16.

20. Hayashi PH, Fontana RJ, Chalasani NP, Stolz AA, et al. Under-reporting and Poor Adherence to Monitoring Guidelines for Severe Cases of Isoniazid Hepatotoxicity. Clinical Gastroenterology and Hepatology. 2015;13(9):1676-82.

21. Ramappa V, Aithal GP. Hepatotoxicity Related to Anti-tuberculosis Drugs: Mechanisms and Management. Journal of Clinical and Experimental Hepatology. 2013;3(1):37-49.

22. Thyagarajan SP, Jayaram S, Gopalkrishnan V, Hari R, Jeyakumar P, Sripathi MS. Herbal medicines for liver diseases in India. Journal of Gastroenterology Hepatology. 2002;17(s3):S370-6.

23. Yesmin F, Rahman Z, Dewan JF, Helali AM, Rahman NIA, Ahmed AG, et al. Hepatoprotective role of aqueous and n-hexane extracts of Nigella sativa L. in experimental liver damage in rats. Asian Journal of Pharmaceutical and Clinical Research. 2013;6(3):205-9.

24. Essawy AE, Abdel-Moneim AM, Khayyat L, Elzergy AA. Nigella sativa seeds protect against hepatotoxicity and dyslipidemia induced by 
carbon tetrachloride in mice. Journal of Applied Pharmaceutical Science. 2012;2(10):21-5.

25. Trivedi M, Chansoria AK, Dixit AK. Protective effect of Thymoquinone against Antitubercular Drug Induced Hepatic Toxicity in Rats. International Journal of Universal Pharmacy and Bio Sciences. 2013;2(1):1-8.

26. Sodhi CP, Rana SV, Mehta SK, Vaiphei K, et al. Study of oxidative stress inisoniazid-rifampicin induced hepatic injury in young rats. Drug and Chemical Toxicology. 1997;20(3):255-69.

27. Houghton PJ, Zaraka R, Delas HB, Hoult JR. Fixed oil of Nigella sativa and derived thymoquinone inhibit eicosanoid generation in leucocytes and lipid peroxidation. Planta Medica. 1995;47(3):119-26.
28. Mansour MA, Ginawi OT, EL-Hiday T, EL-Khatib AS, et al. Effects of volatile oil constituents of Nigella sativa on carbon tetrachloride induced hepatotoxicity in mice: evidence for antioxidant effects of thymoquinone. Research Communication in Molecular Pathology and Pharmacology. 2001;110(3-4): 239-51.

29. Kanter M, Coskun O, Uysal $\mathrm{H}$. The antioxidative and antihistaminic effect of Nigella sativa and its major constituent, Thymoquinone on ethanol-induced gastric mucosal damage. Archives of Toxicology. 2006;80(4):217-24.

30. Ismail M, Al-Naqeep G, Chan KW. Nigella sativa Thymoquinone-rich fraction greatly improves plasma antioxidant capacity and expression of antioxidant genes in hypercholesterolemic rats. Free Radical Biology and Medicine. 2010;48(5):664-72.

\section{ABOUT AUTHORS}

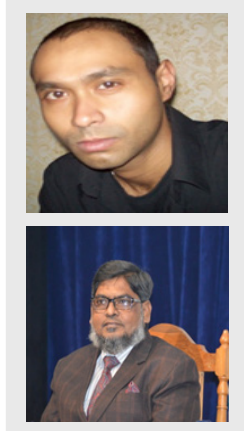

Dr. Joydeep Paul has done MD (Pharmacology) from JNMC, AMU, Aligarh.

\section{SUMMARY}

- N. sativa oil has protective effect against Isoniazid induced Hepatotoxicity.

Prof. Mohammad Nasiruddin working as Professor since 21.7. 2012 and Chairman, Department of Pharmacology J. N. Medical College, AMU Aligarh since 08.08.2017. He is also associated with Pharmacovigilance Programme of India (PvPI) under Ministry of Health and Family Welfare, Government of India as Coordinator of ADR Monitoring Centre at J.N.Medical College, AMU, Aligarh. He has been deputed as $\mathrm{MCl}$ assessor. He has been Expert of different Selection Committees like UPSC Jammu \& Kashmir, Integral University Lucknow. He has been appointed as examiners at SKIMS (Srinagar), RIMS(Ranchi), LHMC(New Delhi), BHU, AMU and several other Universities. He has been associated with research going on in different departments of AMU. I was associated with J. N. Medical College administration and Hall administration as Deputy Medical Superintendent \& warden for several years respectively. He has served the university as Assistant Proctor. During his teaching tenure till date he has attended 13 Conferences, presented 13 Papers and published 38 papers in various national and International journals. He has published two pharmacy Manuals for M.B.B.S. and B.D.S. students of Pharmacology. He has guided 21 M.D. students of Pharmacology, Medicine, J. N. Medical College and Ilmul Advia, A. K.Tibbiya College AMU Aligarh and 5 M.D. Students of Pharmacology, Medicine and Ilmul Advia are working with me.

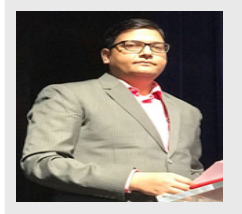

Dr. Irfan Ahmad Khan working as an Assistant Professor in the Department of Pharmacology, J.N.M.C., A.M.U., Aligarh. I did my M.B.B.S. and M.D.(Pharmacology) from J.N.M.C., A.M.U. He has formal training and experience in designing and conducting clinical trials, ADR reporting and causality assessment, Pharmacogenomic studies, teaching pharmacology to MBBS and BDS students. He has published research papers in various national and international indexed journals. He has $1^{\text {st }}$ Prize for oral presentation at $1^{\text {st }}$ Annual Conference of Physiologists and Pharmacologists of India, UP-UK APPICON- 2012. His is presently Editorial Board Member of World Journal of Pharmaceutical Sciences and Journal of Pharmaceutical and Biological Sciences. $\mathrm{He}$ is a reviewer board member of British Journal of Medicine and Medical Research, British Journal of Pharmaceutical Research, Journal of Scientific Research and Reports etc.

Dr. Rahat Ali Khan, Ex-Professor Department of Pharmacology J. N. Medical College Aligarh Muslim University Aligarh India. He is involved in teaching and research for more than 3 decades. Thrust areas of his research are Neuropharmacology, Clinical Pharmacology, Immunopharmacology, Trace element studies, Autacoids-Histamine and Indigenous drugs. About 30 theses of M. D./M.S./Ph.D. he has been guided 54 research papers, mostly in international journals have been published More than 90 research papers has been presented in various national and international conferences. He has many book chapters to his credit. He has also been the member of the reviewer panel and editorial board of various International journals member of various academic bodies and member/ convener of Institutional ethical committee Animal Ethical committee, Bioethical committee of J. N. Medical College AMU Aligarh Director Associate in interdisciplinary brain research center JNMC AMU Aligarh member of University court. He has been member of various scientific bodies including addicted treatment welfare society Pakistan. 
I, Dr. Sayeedul Hasan Arif, has completed MD (Pathology) in 1991 Joined the Department of Pathology, J. N. Medical College, AMU Aligarh (India) as demonstrator for three years and later he joined central lab also known as Lab 21 as Clinical Pathologist in 1993 November for one and half years. Later, he joined the Deparment as Lecturer in 1995, promoted to reader in 2004 and subsequently as an Associate Professor in 2007. Later on he has joined as an Professor in 2010 and presently working on the same post. He is also Incharge Blood Bank and also incharge of central investigation laboratory No 21 at present. He was a member of Medical Education Unit in Faculty of Medicine since 2009 - 2014 and served Hospital in the capicity of DMS from $2011-2013$. He was also a warden of Hadi Hasan Hall from 1995 to 1998 . His date of birth is 22/5/1961. During his studentship he intially was NRSC from 1977 - 1983, Later he was staying in first Mohd Habib Hall from 1983 to 1986 then Hadi Hasan Hall from 1986 to 1991 . He also joined as Provost Hadi Hasan Hall on 10th June 2017.

Cite this article: Paul J, Nasiruddin M, Khan IA, Khan RA, Arif SH. Therapeutic Effect of Nigella sativa Oil in Hepatotoxicity Induced by Isoniazid in Rats. Indian J of Pharmaceutical Education and Research. 2019;53(2):242-9. 